\title{
AVALIAÇÃO DE SUBSTRATOS ORGÂNICOS NA PRODUÇÃO DE MUDAS DE BERINJELA E PIMENTA
}

Mychelle Karla Teixeira de Oliveira

Bolsista de Iniciação Cientifica CNPq/PIBIC, UFERSA, Departamento de Ciências Vegetais, CEP 59.625-900, Mossoró-RN, e-mail:mychelle@ufersa.alunos.edu.br

Francisco de Assis de Oliveira

Eng $^{\circ}$ Agrônomo, Pós-graduando Agronomia, UFERSA, Departamento de Ciências Ambientais, 59.626-310, Mossoró-RN. Email: thikaoamigao@bol.com.br

José Francismar de Medeiros

Bolsista Pesquisa CNPq. Engo . Dr. Depto. Ciências ambientais, UFERSA, Mossoró - RN e-mail:jfmedeir@ufersa.edu.br

Carlos José Gonçalves de Souza Lima

Graduando Agronomia, Bolsista CNPq/PIBIC, UFERSA, Departamento de Ciências Ambientais, CEP 59.625-900, Mossoró-RN, e-mail:kj.gon@bol.com.br

Daniel de Carvalho Galvão

Graduando Agronomia, UFERSA, Departamento de Ciências Ambientais, CEP 59.625-900, Mossoró-RN, e-mail:dcgalvao@bol.com..br

RESUMO - Esse trabalho foi realizado com o objetivo de avaliar substratos orgânicos para a produção de mudas de Berinjela e pimenta. O experimento foi realizado no Departamento de Ciências Vegetais da Universidade Federal Rural do Semi-Àrido (UFERSA). O delineamento experimental utilizado foi em blocos casualizados com três repetições. Os tratamentos constaram dos substratos: fibra de coco (FC), húmus de minhoca (HM), composto orgânico (CO), fibra de coco (FC) + húmus de minhoca (HM) (1:1) e fibra de coco (FC) + composto orgânico (CO) (1:1). As variáveis avaliadas foram: porcentagem de emergência, o índice de velocidade de emergência, massa seca da parte aérea e massa seca da raiz. As espécies estudadas responderam diferentes aos substratos avaliados. Não foi encontrado efeito significativo para a porcentagem de emergência e para o índice de velocidade de emergência. Os melhores desempenhos foram obtidos com a mistura de composto orgânico e/ou húmus de minhoca com pó de coco

Palavras Chave: Solanum melongena, Capsicum spp, propagação, agricultura orgânica

\section{EVALUATION OF ORGANIC SUBSTRATA IN THE PRODUCTION OF SEEDLINGS OF EGGPLANT AND PEPPER}

ABSTRACT - This work was carried through with the objective to evaluate organic substrate for the production of seedlings of eggplant and pepper. The experiment was accomplished in the Department of Vegetable Sciences of the Rural Federal University of the Semi-Arid (UFERSA). The used experimental delineation block was randomized with three repetitions.

Revista Verde (Mossoró - RN - Brasil) v.1, n.2, p. 24-32 julho/dezembro de 2006 http://revista.gvaa.com.br 


\section{REVISTA VERDE DE AGROECOLOGIA E DESENVOLVIMENTO SUSTENTÁVEL GRUPO VERDE DE AGRICULTURA ALTERNATIVA (GVAA)}

the appraised variables were: germination percentage, the emergency index, mass dries of the aerial part and mass dries of the root. The studied species answered different to the appraised substrates. It was not found significant effect for the germination percentage and for the index of emergency speed. The best acting were obtained with the mixture of organic composition and/or earthworm humus with coconut powder

Key Words: Solanum melongena, Capsicum spp, propagation. Organic agriculture

\section{INTRODUÇÃO}

A produção brasileira anual de hortaliças atinge cerca de 12,5 milhões de toneladas (GRANGEIRO e CECÍLIO FILHO, 2004), com projeções de franco crescimento a partir de 2005 (VILELA e HENZ, 2000). Nesse contexto, destacam-se as hortaliças nutracêuticas, que vêm se consolidando no mercado dos fitoterápicos e deverão exercer expressiva contribuição para esse crescimento, isso porque o uso da fitoterapia no Brasil cresce a taxas de 10 a $15 \%$ ao ano, e o seu mercado mundial é da ordem de 20 a 40 bilhões de dólares ao ano (PERECIN, 2001), destacando-se a berinjela e a pimenta.

A berinjela (Solanum melongena L.) é uma solanácea originária das regiões tropicais do Oriente, sendo cultivada há séculos por chineses e árabes. O seu fruto é boa fonte de vitaminas e sais minerais (RIBEIRO et al., 1998). Também lhe são atribuídas propriedades medicinais, como capacidade de diminuir o colesterol plasmático (RIBEIRO JORGE et al., 1998), efeito hipoglicêmico (RIBEIRO et al., 1998), ação vaso dilatadora, efeito diurético e combate à aterosclerose (MEISSEN, 2004), entre outras. A sua capacidade de diminuir o nível de colesterol sanguíneo tem sido contestada (BARONI et al., 2004). Dentre estas a berinjela (Solanum melongena L.), vem despertando interesse por suas propriedades nutracêuticas, existindo evidências de sua ação na redução do colesterol no organismo humano (SANTOS et al., 2000). A área plantada no país é de aproximadamente 1500 ha, com perspectiva de expansão em função do cenário favorável à cultura.

A produção de pimenta (Capsicum spp) para uso como condimento de mesa e de produtos alimentícios industrializados vem crescendo e, atualmente, é uma atividade olerícola bastante rentável, inclusive para pequenas indústrias de conservas. Cinco espécies são comumente cultivadas no Brasil, principalmente no centro-sul e caracterizamse pela pungência, coloração, formato e tamanho dos frutos.O sabor picante dos frutos provém da ação de uma substância denominada capsaicina que é acumulada pelas plantas no tecido da superfície da placenta e é liberada pelo dano físico às células quando se extraem sementes ou corta-se o fruto para qualquer fim.A importância das pimentas é atribuída às suas propriedades melhoradoras de sabor, aroma e cor dos alimentos. Embora tenha baixo valor nutritivo, pode-se destacar o teor vitamínico das pimentas malaguetas verde e vermelha que apresentam valores de 10.500 e 11.000 UI de vitamina A, respectivamente, próximo ao teor de 13.000 UI encontrado na cenoura, considerada uma das melhores fontes desta vitamina. Os teores

Revista Verde (Mossoró - RN - Brasil) v.1, n.2, p. 24-32 julho/dezembro de 2006

http://revista.gvaa.com.br 


\section{REVISTA VERDE DE AGROECOLOGIA E DESENVOLVIMENTO SUSTENTÁVEL GRUPO VERDE DE AGRICULTURA ALTERNATIVA (GVAA)}

de vitamina $\mathrm{C}$ total variam entre as espécies de pimenta, de 160 a 245mg/100g, valores estes comparáveis ao da goiaba (200 $\mathrm{mg} / 100 \mathrm{~g})$ e superiores ao da laranja (60 mg/100g). A comercialização de pimentas in natura têm aumentado nos últimos anos nos principais mercados atacadistas brasileiros, sendo ainda consumidas como temperos em diversos pratos, conservas caseiras, conservas ornamentais em vidros especiais, entre outros usos (REIFSCHNEIDER, 2000).

$O$ cultivo de plantas utilizando substratos é uma técnica amplamente empregada na maioria dos países com horticultura avançada. $\mathrm{O}$ termo substrato aplica-se a todo material sólidos, naturais, sintéticos, residuais, minerais ou orgânicos, distintos do solo, que colocado em um recipiente em forma pura ou em mistura permite o desenvolvimento do sistema radicular, desempenhando, portanto, um papel de suporte para a planta (ABAD \& NOGUERA, 1998).

O mercado orgânico representa $10 \%$ do sistema alimentar na Áustria, cerca de $8 \%$ na Suíça e cresce anualmente a taxas superiores a 20\% nos EUA, na França e no Japão, envolvendo valores entre 23 e 25 bilhões de dólares (FAO, 2003). No Brasil, a área sob cultivo orgânico foi ultimamente estimada em cerca de 270.000 ha, com 1,1\% ocupado pelas hortaliças (ORMOND et al., 2002), e uma estimativa de mercado na faixa de 220 a 300 milhões de dólares. O mercado de produtos orgânicos é pequeno em todo o mundo. Contudo é o seguimento do setor de alimentos que tem apresentado as maiores taxas de crescimento (NEVES, 2005). Com uma área plantada de 842 mil de hectares, o setor movimentou cerca de US\$ 1 bilhão em 2003. O país tem 19 mil propriedades orgânicas certificadas e 174 processadoras espalhadas em diversas regiões (MAPA, 2004). A agricultura orgânica depende do desenvolvimento de sistemas de produção que contemplem o manejo conservacionista do solo e o aporte de nutrientes oriundos de fontes renováveis, com base em resíduos orgânicos localmente disponíveis, de origem vegetal e animal.

$\mathrm{Na}$ agricultura ecológica, a sustentabilidade dos sistemas agrícolas é fator primordial, e a integração de vários sistemas implicará no melhor aproveitamento de recursos disponíveis em uma propriedade, ocasionando assim, um aporte maior de nutrientes para as plantas. Considerando-se a disponibilidade e o baixo custo, tem sido investigada a possibilidade de utilizar, como componentes de substratos, os resíduos agrícolas produzidos em cada região. Assim, observa-se que vários autores desenvolveram pesquisas com os materiais predominantes em suas regiões como bagaço de cana-de-açúcar (BIASI et al., 1995; FERNANDES et al., 2002), composto de resíduos hortícolas (URRESTARAZU et al., 2000), casca de amendoim (FERNANDES et al., 2002), fibra da casca de coco (CARRIJO et al., 2002). Diante do exposto o objetivo deste trabalho foi avaliar a qualidade de mudas de berinjela e pimenta produzida em diferentes substratos orgânicos.

\section{MATERIAL E MÉTODOS}

O experimento foi conduzido no viveiro didático do Departamento de Ciências Vegetais da Universidade Federal Rural do Semi-Árido (UFERSA), em Mossoró, RN. Localizada nas coordenadas geográficas de $5^{\circ}$

Revista Verde (Mossoró - RN - Brasil) v.1, n.2, p. 24-32 julho/dezembro de 2006

http://revista.gvaa.com.br 


\section{REVISTA VERDE DE AGROECOLOGIA E DESENVOLVIMENTO SUSTENTÁVEL GRUPO VERDE DE AGRICULTURA ALTERNATIVA (GVAA)}

$11^{\prime} 31^{\prime \prime}$ de latitude sul e $37^{\circ} 20^{\prime} 40^{\prime \prime}$ de longitude oeste de Greenwich, com altitude média de $18 \mathrm{~m}$. O clima local é do tipo BSwh'com base na classificação de Köppen e a média anual de precipitação é da ordem de $678 \mathrm{~mm}$. As médias anuais de temperatura, insolação e umidade relativa são $27,4^{\circ} \mathrm{C}, 236$ horas anuais e 68,9\% respectivamente (AMARO FILHO, 1991).

$\mathrm{O}$ experimento foi conduzido no Departamento de Ciências Vegetais da UFERSA-RN, no período de outubro a novembro de 2006. A semeadura foi realizada no dia 20/10/2006 em bandejas de poliestireno expandido com 128 células utilizando sementes de berinjela, v. Preta Comprida, e pimenta, v. Cayenne, em copos descartáveis de $180 \mathrm{ml}$, sendo semeadas 5 sementes por copo, deixando-se a mais vigorosa, após desbaste realizado 5 dias após a germinação. $\mathrm{O}$ experimento foi conduzido em condição de telado com $50 \%$ de sombreamento. Durante a condução do experimento foram feitas 2 irrigações diárias (manhã e final da tarde) de forma a deixar a teor de umidade próximo a capacidade de campo.

Utilizou-se o delineamento em blocos casualizados com cinco tratamentos e três repetições, onde a unidade experimental foi representada por 10 mudas, sendo avaliadas 5 destas escolhidas aleatoriamente. Os tratamentos constaram de diferentes substratos orgânicos: fibra de coco (FC), húmus de minhoca (HM), composto orgânico (CO), fibra de coco (FC) + húmus de minhoca (HM) (1:1) e fibra de coco (FC) + composto orgânico (CO) (1:1). R).
Aos 21 dias após a semeadura foram coletadas, 5 plântulas de cada parcela e foram levadas ao laboratório, lavadas em água corrente para a eliminação do substrato. Os parâmetros avaliados foram: porcentagem de emergência (\%E), índice de velocidade de emergência (IVE), massa seca da parte aérea (MSPA) e massa seca da raiz (MSR). A porcentagem de germinação foi calculada de acordo com Labouriau \& Valadares (1976):

$$
\% \mathrm{G}=(\mathrm{N} / \mathrm{A}) \cdot \mathrm{x} 100
$$

Em que;

\%G - Percentagem de germinação.

$\mathrm{N}$ - Número total de sementes germinadas.

A - Número total de sementes semeadas.

O índice de velocidade de emergência (IVE) foi determinado registrando-se diariamente o número de sementes germinadas até o sétimo dia e calculado pela fórmula proposta por Maguire (1962). Foram consideradas como emergidas as plântulas que apresentavam os cotilédones totalmente livres.

$\mathrm{IVE}=\mathrm{E} 1 / \mathrm{N} 1+\mathrm{E} 2 / \mathrm{N} 2 \ldots+\mathrm{En} / \mathrm{Nn}$

Em que;

IVE - Índice de velocidade de emergência.

E1, E2 ... En = Números de plântulas normais emergidas na primeira, segunda até a última contagem.

$\mathrm{N} 1, \mathrm{~N} 2 \ldots \mathrm{Nn}=$ Número de dias da semeadura à primeira, segunda até a última contagem.

Para determinação da matéria seca as plântulas foram postas para secar em estufa de circulação forçada com temperatura de $65^{\circ} \mathrm{C}$ $( \pm 1)$ até atingir peso constante e pesada em balança analítica (Precisão 0,01g). Os dados coletados foram submetidos à análise de variância e as médias comparadas através de gráficos

\section{RESULTADOS E DISCUSSÃO}

O desempenho dos substratos sobre a qualidade das mudas de cada espécie estudadas, foi avaliado isoladamente. A

Revista Verde (Mossoró - RN - Brasil) v.1, n.2, p. 24-32 julho/dezembro de 2006 


\section{REVISTA VERDE DE AGROECOLOGIA E DESENVOLVIMENTO SUSTENTÁVEL GRUPO VERDE DE AGRICULTURA ALTERNATIVA (GVAA)}

análise de variância verificou, para as mudas de berinjela, efeito significativo para massa seca da parte aérea (MSPA) e massa seca da raiz (MSR), ao nível de 0,01 e 0,05 de probabilidade, respectivamente, enquanto que a porcentagem de emergência (\%E) e o índice de velocidade de emergência não apresentaram resposta significativa (Tabela 1). Não foi verificado efeito significativo para percentagem de germinação (\%GER) e índice de velocidade de emergência (IVE), no entanto foi encontrada resposta signifivativa $(\mathrm{p}<0,05)$ para o número de folhas $(\mathrm{NF})$, altura (ALT), fitomassa seca da parte aérea (FSPA) e fitomassa seca da raiz (FSR) (Tabela 1).

Tabela 1. Resumo da análise de variância para porcentagem de germinação (\%GERM), índice de velocidade de emergência (IVE), matéria seca da parte aérea (MSPA) e da raiz (MSR) nas mudas de berinjela produzida em diferentes substratos orgânicos. Mossoró, UFERSA, 2006.

\begin{tabular}{|c|c|c|c|c|c|}
\hline \multirow{3}{*}{$\begin{array}{c}\text { Fontes } \\
\text { de } \\
\text { variação }\end{array}$} & \multicolumn{5}{|c|}{ Quadrados médios } \\
\hline & \multicolumn{5}{|c|}{ Berinjela } \\
\hline & GL & \% GERM & IVE & MSPA & FSR \\
\hline Substratos & 4 & $106,667 \mathrm{~ns}$ & $0,631 \mathrm{~ns}$ & $0,021^{* *}$ & $0,065 * *$ \\
\hline Resíduo & 8 & 181,667 & 0,227 & 0,003 & 0,002 \\
\hline \multirow[t]{2}{*}{ C.V.(\%) } & & 19,44 & 12,63 & 10,42 & 17,22 \\
\hline & \multicolumn{5}{|c|}{ Pimenta } \\
\hline Substratos & 4 & 93,333ns & 0,769ns & $0,00969 * *$ & $0,00208 *$ \\
\hline Resíduo & 8 & 378,333 & 2,495 & 0,00115 & 0,000458 \\
\hline C.V.(\%) & & 25,82 & 23,34 & 13,52 & 25,69 \\
\hline
\end{tabular}

* Significativo a 0,05 e ** a 0,01 de probabilidade; ns - não significativo pelo teste $\mathrm{F}$

\section{Resultados da berinjela}

Analisando os valores médios nos parâmetros avaliados nas mudas de berinjela (Tabela 1),verifica-se que a porcentagem de emergência (\%E) variou entre 66,7 e $80 \%$ entre os tratamentos, no entanto, não verificouse diferença significativa entre os mesmos. Para o índice de velocidade de emergência (IVE) a variação foi de 4,7 a 6,0 plantas/dia, sendo que todos os tratamentos não diferiram estatisticamente. Com relação à massa seca da parte aérea (MSPA), os maiores valores foram encontrados com os substratos húmus de minhoca, composto orgânico e fibra de coco + composto orgânico. Resultados semelhantes foram encontrados por Campanharo et al. (2006) trabalhando com diferentes substratos na produção de mudas de tomateiro, onde se verificou que os a base de composto orgânico proporcionaram maiores valores na matéria seca da parte aérea. Pragana (1988) também encontrou valores inferiores nos substratos à base de fibra de coco, provavelmente esse comportamento se deve ao baixo teor de nutrientes existente na fibra de coco. Para a massa seca das raízes (MSR) o melhor desempenho foi obtido com o composto orgânico e nos demais que continha parte de fibra de coco. Nascimento (2006) trabalhando com mudas de tomate cereja, verificou melhores resultados com composto orgânico. 


\section{REVISTA VERDE DE AGROECOLOGIA E DESENVOLVIMENTO SUSTENTÁVEL GRUPO VERDE DE AGRICULTURA ALTERNATIVA (GVAA)}

Tabela 2. Valores médios para porcentagem de germinação (\%GERM), índice de velocidade de emergência (IVE), matéria seca da parte aérea (MSPA) e da raiz (MSR) nas mudas de berinjela produzidas em diferentes substratos orgânicos. Mossoró, UFERSA, 2006.

\begin{tabular}{lcccc}
\hline \multirow{2}{*}{ Tratamentos } & \multicolumn{4}{c}{ Berinjela } \\
\cline { 2 - 5 } & \% GERM & IVE & MSPA & FSR \\
\hline T1 - PC & $77 \mathrm{a}$ & $4,07 \mathrm{a}$ &, $041 \mathrm{~b}$ & $0,21 \mathrm{bc}$ \\
T2 - HUM & $70 \mathrm{a}$ & $3,07 \mathrm{a}$ & $0,57 \mathrm{a}$ & $0,27 \mathrm{ab}$ \\
T3 - COM & $70 \mathrm{a}$ & $4,28 \mathrm{a}$ & $0,54 \mathrm{ab}$ & $0,16 \mathrm{c}$ \\
T4 - PC + HUM (1:1) & $60 \mathrm{a}$ & $3,18 \mathrm{a}$ & $0,41 \mathrm{~b}$ & $0,16 \mathrm{c}$ \\
T5 - PC + COM (1:1) & $70 \mathrm{a}$ & $3,66 \mathrm{a}$ & $0,57 \mathrm{a}$ & $0,33 \mathrm{a}$ \\
\hline
\end{tabular}

PC - Pó de coco, HUM - húmus de minhoca e COM - Composto orgânico.

Médias seguidas pela mesma letra nas colunas não diferem entre si pelo teste de Tukey a 0,05 de probabilidade

\section{Resultado da pimenta}

Com relação às mudas de pimenta, pode-se observar na tabela 3 que para o número de folhas (NF), apenas $\mathrm{o}$ substrato composto pela mistura de pó de coco + húmus diferiu dos demais, apresentando o menor desempenho. Para altura das plantas (ALT) e a fitomassa seca da parte aérea os resultados foram semelhantes, onde o húmus de minhoca, o composto e a mistura pó de coco + composto apresentaram os melhores resultados, não diferindo entre si, enquanto os piores foram proporcionados pelos substratos pó de coco e pela mistura pó de coco + húmus de minhoca. Resultados semelhantes foram encontrados por Campanharo et al. (2006). Pragana (1988) também encontrou valores inferiores nos substratos à base de pó de coco, provavelmente esse comportamento se deve ao seu baixo teor de nutrientes.
Para a fitomassa seca da raiz os melhores desempenhos foram obtidos com a mistura pó de coco + composto e pelo húmus de minhoca, já os piores foram encontrados no composto isolado e na mistura pó de coco + húmus. Tamiso et al. (2004) trabalhando com composto e húmus de minhoca na produção de mudas de tomate, verificou que as melhores mudas foram obtidas utilizando-se $100 \%$ de composto orgânico produzido a partir de esterco bovino e palha de milho na proporção de 3:1, respectivamente. O mesmo autor observou que a adição de húmus de minhoca na formação do substrato promoveu um decréscimo da altura e da massa seca da parte aérea das plântulas. Resultado semelhante foi encontrado por Nascimento (2006). 


\section{REVISTA VERDE DE AGROECOLOGIA E DESENVOLVIMENTO SUSTENTÁVEL GRUPO VERDE DE AGRICULTURA ALTERNATIVA (GVAA)}

Tabela 2. Valores médios para porcentagem de germinação (\%GERM), índice de velocidade de emergência (IVE), matéria seca da parte aérea (MSPA) e da raiz (MSR) nas mudas de pimenta produzidas em diferentes substratos orgânicos. Mossoró, UFERSA, 2006.

\begin{tabular}{lcccc}
\hline & \multicolumn{4}{c}{ Pimenta } \\
\cline { 2 - 5 } \multicolumn{1}{c}{ Tratamentos } & \% GERM & IVE & MSPA & MSR \\
\hline T1 - PC & $80 \mathrm{a}$ & $6,0 \mathrm{a}$ & $0,195 \mathrm{~b}$ & $0,067 \mathrm{ab}$ \\
T2 - HUM & $80 \mathrm{a}$ & $4,7 \mathrm{a}$ & $0,320 \mathrm{a}$ & $0,051 \mathrm{~b}$ \\
T3 - COM & $77 \mathrm{a}$ & $4,8 \mathrm{a}$ & $0,293 \mathrm{a}$ & $0,117 \mathrm{a}$ \\
T4 - PC + HUM (1:1) & $74 \mathrm{a}$ & $5,3 \mathrm{a}$ & $0,248 \mathrm{ab}$ & $0,101 \mathrm{ab}$ \\
T5 - PC + COM (1:1) & $67 \mathrm{a}$ & $5,0 \mathrm{a}$ & $0,195 \mathrm{~b}$ & $0,083 \mathrm{ab}$ \\
\hline
\end{tabular}

PC - Pó de coco, HUM - húmus de minhoca e COM - Composto orgânico.

Médias seguidas pela mesma letra nas colunas não diferem entre si pelo teste de Tukey a 0,05 de probabilidade

De acordo os as tabelas acima (Tabelas 2 e 3 ) os substratos proporcionaram respostas diferentes nas culturas estudadas, demonstrando a necessidade de pesquisas específicas para cada espécie.

\section{CONCLUSÕES}

As espécies estudadas responderam diferentes aos substratos avaliados

Os melhores desempenhos foram obtidos com a mistura de composto orgânico e/ou húmus de minhoca com pó de coco

\section{LITERATURA CITADA}

ABAD, M.; NOGUERA, P. Substratos para el cultivo sin suelo y fertirrigación. In: CADAHIA, C. (Ed.) Fertirrigación: cultivos hortícolas y ornamentales. Madrid: Mundi Prensa, 1998. p.287342.

AMARO FILHO, J. Contribucion al estúdio Del clima del Rio Grande do Norte. 1991. 11f. Tese (Doutorado) ETSIA/UPM, Madrid. 1991.
BARONI, E.A.; NATALI, M.R.M.; BATISTA, M.R.; SANTOS, E.R. Efeito da berinjela (Solanum melongena) nos lipídeos plasmáticos e na morfologia do fígado de coelhos hipercolesterolêmicos. International Journal of Morphology, v. 22, n. 1, p. 35-101, 2004.

BIASI LA; BILIA DAC; SÃO JOSÉ AR; FORNASIERI JL; MINAMI K. Efeito de misturas de turfa e bagaço-de-cana sobre a produção de mudas de maracujá e tomate. Scientia Agrícola, Piracicaba., v.52, p.239243. 1995.

CAMPANHARO, M.; RODRIGUES, J. J. V.; LIRA JÚNIOR, M. A.; ESPINDULA, M. C.; COSTA, J. V. T. Características físicas de diferentes substratos para produção de mudas de tomateiro. Caatinga. Mossoró, v.19, n.2, p.140-145, 2006.

CARRIJO, O.A.; LIZ, R.S.; MAKISHIMA, N. Fibra da casca do coco verde como substrato agrícola. Horticultura Brasileira, Brasília, v. 20, n. 4, p. 533-535, 2002.

Revista Verde (Mossoró - RN - Brasil) v.1, n.2, p. 24-32 julho/dezembro de 2006 http://revista.gvaa.com.br 
FAO. World agriculture: towards 2015/2030 FAO perspective. Disponível em: http://www.fao.org/organicag>. Acesso em: agosto de 2003.

FERNANDES C; ARAÚJO JAC; CORÁ JE. Impacto de quatro substratos e parcelamento da fertirrigação na produção de tomate sob cultivo protegido. Horticultura Brasileira, v.20, p.559-563, 2002.

GRANGEIRO, L.C.; CECÍLIO FILHO, A.B. Exportação de nutrientes pelos frutos de melancia em função de épocas de cultivo, fontes e doses de potássio. Horticultura Brasileira, v. 22, n. 4, p.740-743, 2004.

MAGUIRE, J.D. Speed of germination aid in selection and evaluation for seedling emergence and vigor. Crop Science, Madison, v.2,n.2, p176177,1962.

MAPA, Mistério da Agricultura, Pecuária e Abastecimento. Publicação eletrônica: Agricultura brasileira em números/Anuário 2004. Brasília. Disponível em:<http://www.agricultura.gov.br $>$ Acesso em 06/01/06.

MEISSEN. Indicador natural de saúde. Cotia, SP, 2004. Folder.

NASCIMENTO, C. F.; AZEVEDO, C. M. S. B.; MEDEIROS, D. C.; BELÉM, T. P.; MOREIRA, J. N.; PINHEIRO, M. D. C.; DANTAS, M. R. S.; MARQUES, L. F.; GERHARDT, M. A.; SANTOS, S. C. L. Produção de mudas de tomate cereja em diferentes substratos e em efluente de piscicultura e água de poço tubular, em sistema orgânico. In: XLVI CONGRESSO BRASILEIRO DE OLERICULTURA, 2006, Gioania, Anais... CD-ROM.

NEVES, M.C.P. Agricultura Orgânica na União Européia. In: AQUINO, A.M.; ASSIS, R.L.(Ed). Agroecologia princípios e técnicas para uma agricultura sustentável. Brasília: Embrapa Agrobiologia, 2005. p 201-214.

ORMOND, J.G.P.; PAULA, S.R.L.; FAVERET FILHO, P.; ROCHA, L.T.M. Agricultura orgânica: quando o passado é futuro. Rio de Janeiro: BNDES, 2002. 35p.

PERECIN, M.B. Produção e mercado de plantas medicinais, aromáticas e condimentares: perspectivas para o pequeno produtor. In: CONGRESSO BRASILEIRO DE HORTICULTURA ORGÂNICA, NATURAL, ECOLÓGICA E BIODINÂMICA, 1., 2001, Botucatu. Resumos... Botucatu: Agroecológica, 2001. p.136-139.

PRAGANA, R. B. Potencial do resíduo da extração da fibra de coco como substrato na produção agrícola. 1998. 84 f. Dissertação (Mestrado) - Universidade Federal Rural de Pernambuco, Recife. 1988.

REIFSCHNEIDER, F. J. B. Capsicum pimentas e pimentões do Brasil. Brasília: Embrapa Comunicação para Transferência de Tecnologia/Embrapa Hortaliças, 2000. 113p.

RIBEIRO JORGE, P.A.; NEYRA, L.C.; OSAKI, R.M.; ALMEIDA, E.; BRAGAGNOLO, N. Efeito da berinjela sobre os lípedes plasmáticos, a peroxidação lipídica e a reversão da disfunção endotelial na hipercolesterolemia experimental. Arquivos

Revista Verde (Mossoró - RN - Brasil) v.1, n.2, p. 24-32 julho/dezembro de 2006

http://revista.gvaa.com.br 
Brasileiros de Cardiologia, v. 70, n. 2, p. 87-92, 1998.

RIBEIRO, C.S. da C.; BRUNE, S.; REIFCHNEIDER, F.J.B. Cultivo da berinjela. Brasília: Embrapa Hortaliças, 1998. 23 p. (Embrapa Hortaliças. Instrução Técnica 15).

SANTOS, H.S.; BORGES, L.M.; CALLEGARI, O. Influência da poda na produtividade da berinjela. Horticultura Brasileira, Brasília, v. 18, p.557-558, Suplemento, 2000.

URRESTARAZU M; SALAS MC; RODRÍGUEZ R; ELORRIETA MA; MORENO J. Evaluación agronómica del uso del compost de residuos hortícolas como sustrato alternativo en cultivo sin suelo en tomate. Actas de Horticultura, Wageningen, n.32: 327332., 2000.

LABOURIAU, L. G. \& VALADARES, M. B. On the germination of seeds of Calotropis procera. Anais da Academia Brasileira de Ciências, São Paulo, n.48, p.174-186. 1976

TAMISO, L. G.; ROSSI, F.; MELO, P. C. T.; AMBROSANO, E. J.; CHIAVEGATO, E. J.; GUIRADO, N.; MENDES, P. C. D. ; SCHAMMASS, E. A.; AMBROSANO, G. M. B.; ENDO, G. K.; MANFREDINI, D. Produção de mudas de tomate em composto orgânico e húmus de minhoca. Horticultura Brasileira. V. 22, n.2 julho 2004. Suplemento CDROM.
VILELA, N.J.; HENZ, G.P. Situação atual da participação das hortaliças no agronegócio brasileiro e perspectivas futuras. Cadernos de Ciência \& Tecnologia, v. 17, n. 1, p. 71-89, 2000. 